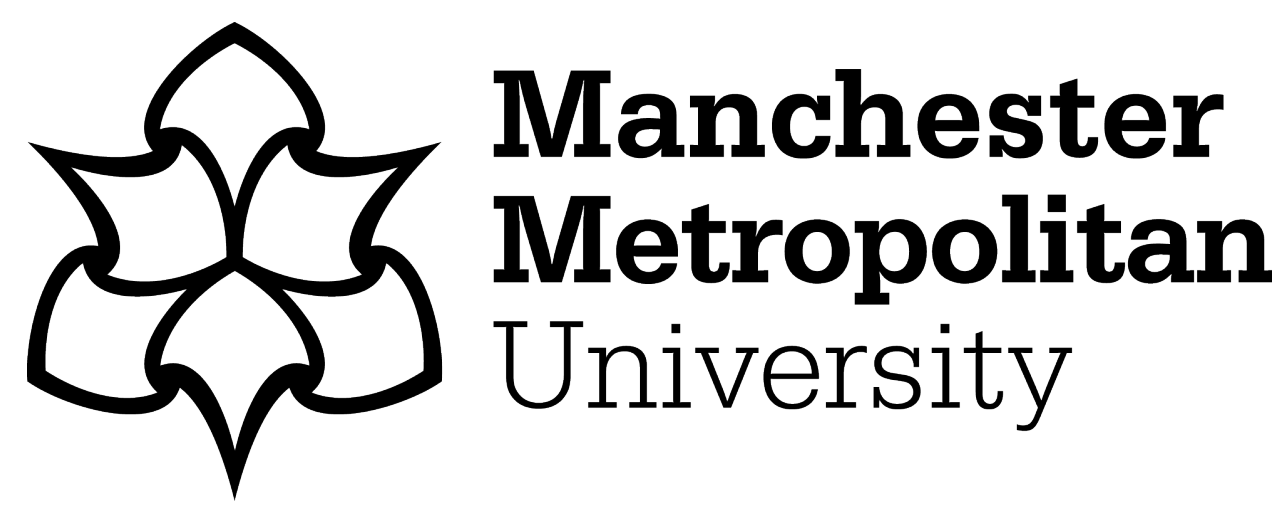

Córdoba-Pachón, JR and Paucar-Caceres, A (2019) The Unfolding and Resurfacing of Information Systems Knowledge over the Last 25 Years: A Systemic Perspective. Systems Research and Behavioral Science, 36 (4). pp. 445-460. ISSN 1092-7026

Downloaded from: https://e-space.mmu.ac.uk/621921/

Version: Accepted Version

Publisher: Wiley

DOI: https://doi.org/10.1002/sres.2558

Please cite the published version 


\title{
The unfolding and resurfacing of information systems (IS) knowledge over the last 25 years: A systemic perspective
}

\begin{abstract}
Currently there are many perspectives aiming to account for what the field of information systems (IS) is or should be. For some, IS is conceived as a reference and stable discipline with dominant or core knowledge to export to other disciplines. To others, IS still requires a more eclectic/fluid perspective to enable IS be adaptable to emerging challenges and possibilities. In both types of perspectives, there is a need to appreciate fully how ISknowledge has effectively unfolded through time in broader contexts of social sciences. In line with an emerging research orientation to conceive the IS field as both dominant and eclectic, we propose a systemic framework to account for these stages. We identify key IS knowledge concepts/themes emerging from analysing 4,100 abstracts from articles in eight IS journals covering EU/US regions over the last 25 years. Our findings suggest that such knowledge does not accumulate but rather, some IS key concepts like systems, information and use resurface over time, leading to draw important implications for IS education, research and practice.
\end{abstract}

Keywords: information; systems; dominance; eclecticism; content analysis; use; Andrew Abbott; Leximancer ${ }^{\circledR}$ 


\section{Introduction}

Currently there are many perspectives aiming to account for what the field of information systems or IS is or should be. Some commentators have argued that IS can be conceived of as a stable field that can export relevant knowledge to other academic or practical settings (Baskerville \& Myers, 2002; Benbasat and Zmud, 2003; Sidorova et al, 2008; Hassan, 2011; Hassan and Mathiassen, 2017). To others, a more diverse, eclectic or fluid perspective is required to enable the field to be adaptable to emerging knowledge challenges (Bryant, 2008; Hirschheim and Klein 2008). Between these types of perspectives there could be a spectrum of alternatives suggesting that the IS field needs alternative understandings about itself (Galliers, 2003; Schwartz 2014; Wade et al, 2006).

This paper proposes and validates a systemic framework that considers both knowledge dominance and eclecticism as mutually dependent stages of the unfolding of the IS field. In this regard, the paper aligns with an emerging orientation that conceives of IS as potentially exhibiting both dominance and eclecticism at different times. The framework is inspired in the sociologist Andrew Abbott's ideas and complements existing research on the dynamics of the field of IS (Wade et al, 2006; Sidorova et al, 2008; Córdoba-Pachón, Pilkington and Bernroider, 2012; Bernroider, Pilkington and Córdoba-Pachón, 2013; Liu et al, 2016).

Using a software tool (Leximancer ${ }^{\circledR}$ ), we adapt the method of analysis of IS literature by Bandara et al (2015) to identify relevant concepts, themes and associations between them and elicit different stages of knowledge of dominance and eclecticism in a period of 25 years and using 4,100 abstracts in eight prominent IS journals. Although our study does not intend to provide comprehensive syntheses or theoretical contributions about IS knowledge, the findings suggest that IS key concepts like systems, information and use reconfigure as well as resurface over time, helping the field keep a healthy balance and mutual dependence between dominance and eclecticism. This resurfacing of concepts could have several and important implications for IS research, education and practice.

The article is organized as follows. In section two we outline two main perspectives about the IS field that embrace debates about its status. In section 3, we discuss ideas from Andrew Abbott's sociology of knowledge which provides the theoretical background to formulate a systemic framework. In section 4, we outline the methodology that implements the framework in relation to the IS abstracts included in the study. In section 5, the findings 
across the full stretch of 25-years are presented and then discussed. Finally, in section 6 a set of implications and conclusions are advanced to inform future research, education and practice in the field of IS.

\section{Perspectives to study the field of Information Systems (IS)}

Through the history of the field of information systems or IS, several types of perspectives to explain what the IS field is/should be about have emerged (Hirschheim and Klein, 2012). Some IS researchers propose having a dominant, stable and accumulative set of knowledge elements which would enable the field to retain (if not increase) its degree of social legitimacy as a reference discipline (Baskerville and Myers, 2002). These elements include: IS development and management processes; human behaviours influencing or resulting from these processes; models, methods and concepts for software coding, testing and quality assurance; representations of data, events and systems structures; expert, decision support, collaborative and transactional application systems (Benbasat \& Zmud, 2003; Davis, 2000; IIvari et al., 2004). Other knowledge elements more related to areas of interest and impact of the IS field include: Information Technology (IT) and markets; IT and organizations; IT and groups; IT and individuals; IS strategy, Internet Applications, qualitative methods and interorganisational systems (Sidorova et al., 2008; Taylor et al., 2010).

An alternative type of perspective about IS promotes permeability, diversity, flexibility and continuous adaptability (Vessey et al, 2002; Galliers, 2003; Wade et al., 2006; Bryant, 2008; Klein and Hirschheim, 2008; Hirschheim and Klein, 2012). In this type of perspective, IS can be better regarded as a field/discipline which has been in a continuous state of flux and hence, IS knowledge is best regarded as eclectic, emerging from interactions within and beyond the field, leading to continuous review of what IS is or could be (Bryant, 2008).

Several studies (both conceptual and empirical) to conceive of the IS field could be regarded as emphasising dominance, eclecticism or both. Stability-driven perspectives include IS as a set of accumulative bodies of knowledge in specific areas, for instance paradigm or design science oriented IS research (Chen and Hirschheim, 2004; Love and Hirschheim, 2016; Wagner, Prester and Schryen, 2017). A slightly more eclectic perspective suggests core and peripheral IS knowledge elements (Vessey et al, 2002; Taylor et al, 2010; Liu et al, 2016). Moving towards eclecticism, IS can be also regarded as a group of connected communities of 
practice (Hirschheim and Klein, 2008), or a 'system' of purposeful activities that connect social contexts with IT artefacts (Galliers, 2003; Wade et al, 2006; Lee, 2010).

Whilst all these efforts could be valuable to help IS researchers and practitioners make sense of the relevance of the field vis-à-vis others, there is still an emphasis on the search, identification or disregard of IS knowledge-products, activities or outputs at the potential expense of understanding how and through time, these have come or gone. It is not clear yet -if and how-, some of the identified IS knowledge elements or activities resurface or morph into new ones.

Reflecting about the history of IS, Lee (2010) calls for a rethink or review of how some key IS knowledge concepts (i.e. information, theory, system, organisation) have been taken for granted or even neglected in their use. Lee notices how the understanding and use of the term 'information system' in the IS field requires critical consideration of how other systems ('requirements', 'data' and 'technology') co-vary or co-evolve with it, something that is neglected when using models (i.e. technology acceptance) to guide IS research. From this, it becomes important to explore the dynamics and diversity of IS knowledge elements as well as their associations through time, if more comprehensive ideas about the IS field are to emerge.

This claim echoes what Hirschheim and Klein (2012) have found about the IS field in their historical account: There could be different periods or eras characterised by technological and mind shift events, with some key ideas transiting through them whereas others becoming influential or even resurfacing at a later stage. Hirschheim and Klein (2012) and Klein and Hirschheim (2008) suggest that a more in-depth study of different IS 'eras' and transitions between them could shed light into how the field has unfolded and could inform future thinking and practice in the field.

Related to these above claims, an emerging research direction to study the dynamics of the IS field currently focuses on acknowledging that at different times, both stability (dominance) and fluidity (eclecticism) could be perceived to become a system of mutually dependent stages field (Galliers, 2003; Wade et al, 2006; Córdoba-Pachón, et al, 2012; Bernroider et al, 2013). Córdoba-Pachón et al (2012) and Bernroider et al (2013) have identified and associated time periods in the history of IS with cycles of knowledge conflict, competition and absorption as revealed by networks of citations used in IS journals. These authors leave 
open the opportunity to better understand what IS knowledge remains 'dormant' in the history of the IS and could be used to develop creative possibilities for the future.

This paper aims to contribute to validate the above claims by focusing on identifying potential cycles of knowledge dominance and eclecticism in the IS field. From this, we aim to assess which knowledge concepts or themes (could) play a key role in bringing new or better opportunities for research and practice. Through exploring cycles of dominance and eclecticism, the aim is to assert how and if knowledge in the IS field unfolds and resurfaces, so that a richer understanding can be built for the future.

\section{A systemic perspective on the dynamics of knowledge}

The sociologist Andrew Abbott has provided a detailed account of the dynamics of knowledge in different analytical and physical locations (Abbott, 1988, 2001, 2004). One of these locations is that of universities. At universities, there could be at a given time established disciplines as well as settlements; the latter can be regarded as groups of individuals who have a degree of control over certain problems through activities of research and instruction and which contribute to reassemble knowledge by linking it to societal values. According to Abbott, both disciplines and settlements continuously interact with each other as 'amoebas putting out pseudopods' into areas of knowledge to which they have not control. They do so in order to gain if not maintain their own legitimacy. The coupling of external events and continuous internal interaction results in the dominance of some groups over others. This can be evidenced in the emergence of accepted knowledge via textbooks, ideas, models or theories from the dominant ones.

Through time, knowledge becomes further validated via $\mathrm{PhD}$ empirical research which gives rise to doubts and debates coming from subordinated or emerging groups. A stage of eclecticism can then be perceived. There is no clear 'winner' group or subgroup until internal (new data, quirky or novel ideas, external events) influences the demise of dominant knowledge and its replacement. The situation can be illustrated in the following diagram: 


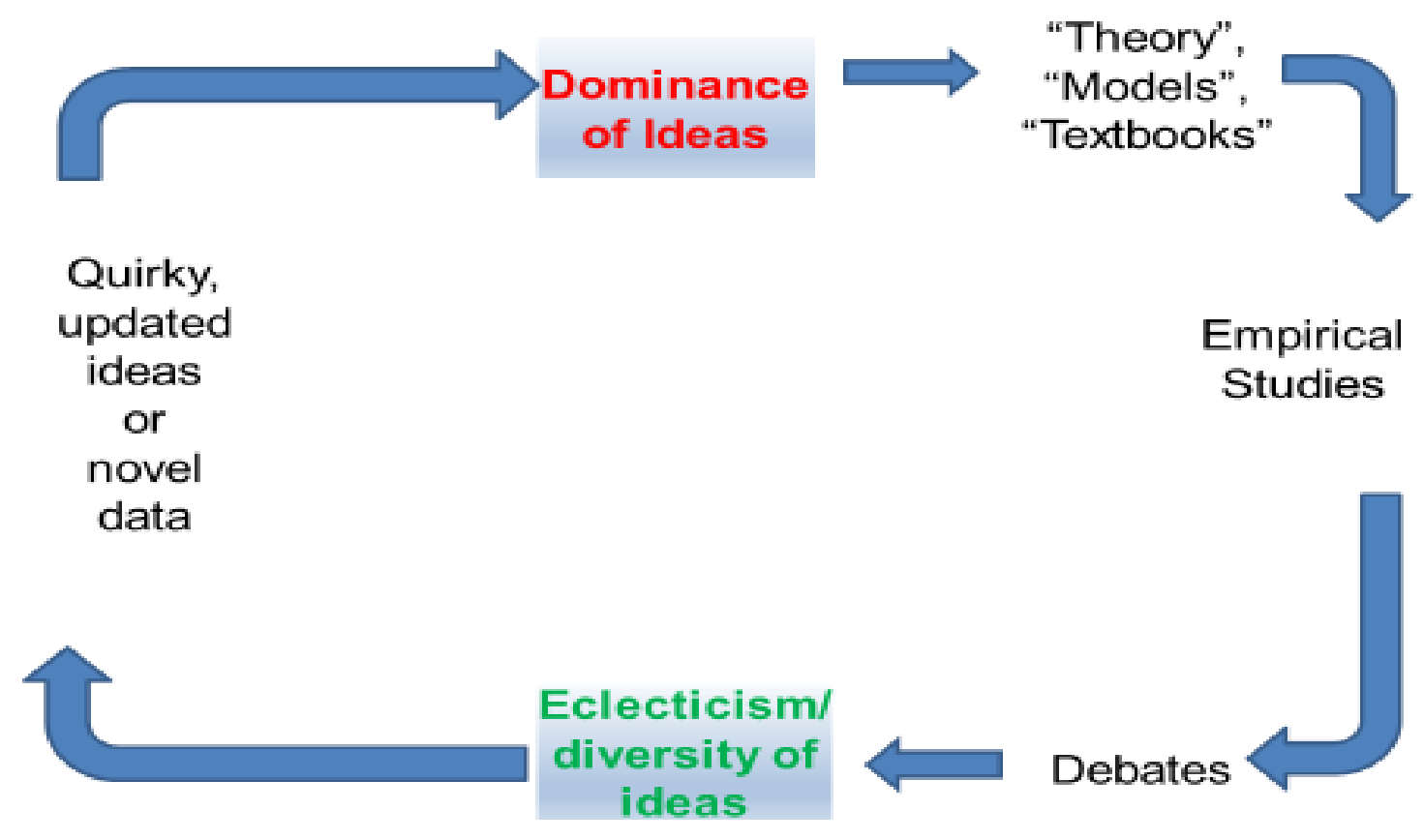

Figure 1. Cycles of dominance and eclecticism (adapted from Abbott, 2001).

However, for Abbott, this does not mean that new and incumbent knowledge is very different from the previous one. Instead, for Abbott (2001) this means that knowledge could resurface or be rediscovered regardless of where this happens so that society keeps hold of key knowledge. Abbott states:

"there is [always] an episode of [knowledge] conflict, then a defeat of one side, division of the winners, and remapping of the losers' concerns onto the equivalent descendant of the winners... [old] ideas return under new names...we get to keep our best ideas whilst yet retaining our belief in perpetual, intellectual progress" (Abbott, 2001, pp.18, 23-25, italics and brackets added).

For those advocating either dominance or eclecticism in the field, this is not entirely bad news though. It could well be that either of these camps needs to learn from each other. For Abbott (2004), knowledge rediscovery could give social science researchers the possibility of identifying diverse strategies for knowledge generation that have been followed by others, and reflect on what other strategies that have not been used much could be better understood or pursued. Creativity in the social sciences becomes more a process of heuristic borrowing and reformulation than an isolated discovery from scratch. 
Moreover, and regardless of their perceived dominance or eclecticism, fields of knowledge like IS (more akin to a settlement according to Abbott, 1988, 2001) could be thus conceived of as helping to maintain key knowledge elements in society. Exploring these dynamics could help IS researchers and practitioners identify possibilities to become more aware of what has/not worked in the past, and then generate alternative ways of studying IS phenomena. Rather than doing this in isolation, creativity in the IS field could be better enhanced by identifying highly or less travelled routes to navigate through an already complex and fluid 'knowledge maze' (Abbott, 2001; Hirschheim and Klein, 2012), and with a view to enhance collective dialogue within as well as beyond it (Abbott, 2001; Bernroider et al, 2013). This could open possibilities for future IS education, research and practice.

To guide our study, we therefore formulate the following research questions:

RQ1: What insights can a systemic perspective (based on cycles of knowledge dominance and eclecticism of the field of IS) offer for a better understanding of the field's knowledge?

RQ2: What implications could be derived from the potential resurfacing of elements of knowledge in the IS field?

To address these questions a methodology is proposed and implemented in the next sections of the paper.

\section{Methodology}

For the IS field, the activity of reviewing IS knowledge has gained structure and insights in the last few years. For instance, Rowe (2014) suggests that a study of the IS literature needs not only to summarise, but also critically consolidate existing IS knowledge as well as be aligned with the study's specific goals. Critical consolidation is about identifying thematic or research gaps and proposing stimulating research directions. An IS study goals could be: describe, understand and explain (i.e. of a specific phenomenon in the IS field or of the field as a whole) (Ibid).

In practice however, Rowe (2014) argues that it could be difficult to separate or achieve all these goals, as any of them involves a degree of judgment and interpretation by those conducting a study in relation to the data used and the logical argument proposed. He nevertheless suggests that rigor and scope need to be explicitly considered and declared in 
studies. This is echoed by Paré et al (2015) who, in undertaking an assessment of IS reviews distinguish a typology of various IS research syntheses based on their different dimensions. Like Rowe (2011), these authors distil differences between simple and more complex and critical accounts of IS knowledge. It is also essential to distinguish the sort of contributions that reviews aim to provide in the light of chosen data and the processes followed.

Following these authors, our declared intention in this study is not to generate a fully comprehensive consolidation or synthesis IS knowledge. We neither focus on drawing any theory out of our interpretations. Rather, we provide a view of the IS field that uses a conceptual framework informed by Abbott's ideas to understand dominance/eclecticism dynamics of IS knowledge, and with the intent of distilling relevant implications for IS research and practice in the light of these dynamics.

We therefore propose reviewing IS knowledge by considering two mutually stages of a) Dominance and b) Eclecticism as well as relations between them. Dominance can be perceived when some IS knowledge elements and their associations become prevalent and stable in the IS literature. Through time, these elements and associations split, become fragmented or reorganised, and other elements appear as new (Eclecticism). After eclecticism, new stages of dominance could appear through emergence, resurfacing and / or absorption of elements as seen illustrated in Figure 2. 




Figure 2. A proposed framework to explore Knowledge Dynamics: Dominance and Eclecticism in IS over time (Adapted from Abbot 2001)

As the above figure shows, we employ content analysis of academic IS journal abstracts of the period 1990-2014. Content analysis concerns with the semantic study of bodies of knowledge. It involves conceptual analysis (text material and its frequency) and relational analysis (co-occurrence and proximity of text material) (Weber, 1990; Smith and Humphreys, 2006). In practice, content analysis can be implemented using different methods. In our study, we adopt Bandara et al (2015)'s method for IS literature reviews. This is one among many possible ones. We selected it, as it enables us to systematically identify and associate relevant IS knowledge elements whilst enabling us to iterate in our analysis and interpretation with the help of software tools. Bandara et al (2015)'s method suggests four stages: (1) extraction of relevant IS literature; (2) organisation and preparation for analysis; (3) Coding (including mapping of associations between concepts using Leximancer ${ }^{\circledR}$ ) to support iterative analysis; and (4) write up and presentation.

The above stages are detailed as follows. The last stage is shown in a separate section (5, findings) of the paper. 


\subsection{Extraction of relevant literature}

Following the Association of Business Schools (ABS, 2015) ${ }^{1}$ we selected eight (8) highly rated IS journals (rated 3 or 4 star) from its 2015 list. To ensure a balance of US-EU research, we decided to include an equal number of US and EU-based journals. The US-based journals were: (1) Management Information Systems Quarterly; (2) Information Systems Research (ISR); (3) Journal of Management Information Systems (JMIS); and Journal of the Association for Information Systems (JAIS). The EU-based journals selected were: (1) Information System Journal (ISJ; (2) Journal of Information Technology; (3) European Journal of Information Systems (EJIS), and (4) Information and Organization (IO). This provided enriched content and enabled a more diverse identification of knowledge distinctions relevant to practitioners and other academic audiences.

The time range for our survey was a 25-year range (January 1990 to December 2014). Following Abbott (2001), a quarter of a century is an adequate timespan to identify cycles of dominance and eclecticism in social sciences. Analysis of IS per decades has been already proposed by Sidorova et al, (2008), Hirschheim and Klein (2012), and Liu et al (2016). We split the range into two decades (1990-99; and 2000-10) and half a decade (2011-204). Although the last period is half the size of the others, we considered the number of abstracts balanced along the periods $(1,060$ articles in the $1990 \mathrm{~s} ; 20,247$ in the $2000 \mathrm{~s} ; 1,140$ in the 2010s).

Overall, we inspected 4,111 articles distributed as follows: MIS Quarterly (514); Information Systems Research (661); Journal of Management Information Systems (753); Journal of the Association for Information Systems (405); Information System Journal (427); Journal of Information Technology (530); European Journal of Information Systems (643); and Information and Organization (178).

\subsection{Organisation and preparation for analysis}

For each of the above articles in the 8 journals considered, relevant information (date, author, title, abstract and keywords) was organised ready for input into Leximancer ${ }^{\circledR}$. Leximancer ${ }^{\circledR}$ is a software tool that helps identify word concepts and, based on their proximity in the text, clusters them and displays the results in a user-friendly visual map (Smith and Humphreys,

\footnotetext{
${ }^{1}$ Academic Journal Guide 2015, http://gsom.spbu.ru/files/abs-list-2015.pdf
} 
2006; Cretchley, 2010; Smith, 2003, Bandara et al, 2015). For our study, Leximancer ${ }^{\circledR}$ helped us to automatically parse text, identify relevant concepts, associations between concepts and their clustering into themes. The final and meaningful identification of concepts, themes is down to the researchers conducting the study (Cretchley, 2010; Bandara et al, 2015).

\subsection{Coding to support iterative analysis}

After the automatic identification and clustering process, we proceeded to review and rename some of the emerging themes generated by the software. In some instances, we kept the original names provided by Leximancer ${ }^{\circledR}$. In others, we interpreted the theme and gave it a different name, validating our interpretations with fellow academic colleagues working in the IS field. We then organised emerging concepts, themes and associations into different time periods or eras, and provided interpretations of each using our conceptual framework.

For each decade, we now present a figure and a table. The figure depicts the themes as generated by Leximancer ${ }^{\circledR}$; themes are indicated as coloured circles coded (hottest indicating the most prominent). Because of the amount of data (4000+ abstracts) used to generate these maps, the text of the labels naming each theme and associated concepts overlap and may made the reading a bit difficult. To help the reading, for each figure we have included the corresponding table.

The table contains information about the most prominent themes and concepts in the IS literature in each decade analysed. In each table, themes (column 1) were those initially identified and labelled by Leximancer ${ }^{\circledR}$. Column 2 shows the re-labelled themes by us after studying the underlying concepts and associations. A measure of connectedness between concepts under each theme is included in column 3. Details of the basis of the authors' interpretation of each theme is included in column 4.

\section{Findings}

\subsection{The 1990's: the emergence and prevalence of the concept 'Systems'}

Table 2 and Figure 3 below indicate that in the 1990s the most prominent IS theme and concept is Systems and use in the IS field. This seems to indicate the earlier preoccupation with understanding the meaning of these concepts and its relationships with others like 
information, technology and organisations. The decade also shows the influence of previous ones in which different conceptual or theoretical approaches including systems thinking and socio-technical were used to conceptualise design, implementation and use of information systems (Hirschheim and Klein, 2012). Additional evidence of this is the concern with studying organisational processes and IS for management which in other studies is conceived of decision support systems or DSS (Sidorova et al, 2008; Hirschheim and Klein, 2012; Liu et al, 2016).

In this study and via the concept of systems, this concern broadens. The theme/concept of systems mediates between technology implementation, organisational management and research concepts. It could be said that it acts as a hinge by bringing together these separate areas of IS knowledge. In addition, the theme of information systems use (theme 2) has a dual function: as a tool-theme competing with or enabling competition within the theme of research concepts (theme 5) or as a phenomenon to explore (IS individual or group use).

These findings extend those initially proposed by Hirschheim and Klein (2012) and CórdobaPachón et al (2012). Within this period, it can be said that not only there was a differentiation or eclecticism between positivism and anti-positivism in the IS field, but also that information and systems played a key role in facilitating it by enabling such eclecticism to emerge. The appearance of other themes like: use (theme 2), analysis (theme 8 including the concepts of analysis itself, theory and methods) and research concepts (theme 5 including research, case, approach, problem) confirm this degree of eclecticism in this decade regarding how IS knowledge is generated and also in relation to the focus of IS activity (impact or firms/sector based). 
Table 2: Most prominent themes and concepts in the IS literature from 1990 to 1999

\begin{tabular}{|c|c|c|c|}
\hline Theme (1) & $\begin{array}{l}\text { Concepts Clustered in } \\
\text { each theme (2) }\end{array}$ & $\begin{array}{l}\text { Connectivity } \\
\text { (3) }\end{array}$ & $\begin{array}{l}\text { Focus for our Interpretation } \\
\text { of each Theme }\end{array}$ \\
\hline 1. Systems & $\begin{array}{l}\text { systems, information, } \\
\text { development, } \\
\text { framework }\end{array}$ & $100 \%$ & $\begin{array}{l}\text { Information systems activity } \\
\text { via conceptual and research } \\
\text { frameworks for studying IS } \\
\text { development and } \\
\text { implementation in } \\
\text { organisations }\end{array}$ \\
\hline 2. Use & $\begin{array}{l}\text { use, model, provide, } \\
\text { design, data, analysis, } \\
\text { based }\end{array}$ & $75 \%$ & $\begin{array}{l}\text { Design of models to gather data } \\
\text { about IS use, provision and } \\
\text { learning by users }\end{array}$ \\
\hline $\begin{array}{l}\text { 3. Organisational Dynamics } \\
\text { Management }\end{array}$ & $\begin{array}{l}\text { management, } \\
\text { organizations, } \\
\text { implementation, } \\
\text { important }\end{array}$ & $56 \%$ & Managing information systems \\
\hline $\begin{array}{l}\text { 4. IS operations - } \\
\text { Technology }\end{array}$ & $\begin{array}{l}\text { process, support, } \\
\text { decision, structure, work }\end{array}$ & $49 \%$ & $\begin{array}{l}\text { Strategic and business IS and } \\
\text { technology roles }\end{array}$ \\
\hline 5. Research concepts & $\begin{array}{l}\text { technology, } \\
\text { organizational, } \\
\text { business, change }\end{array}$ & $47 \%$ & $\begin{array}{l}\text { Projects, cases, frameworks for } \\
\text { software development }\end{array}$ \\
\hline 6. Process & $\begin{array}{l}\text { research, users, } \\
\text { approach, problem }\end{array}$ & $47 \%$ & Relationship IS- work structures \\
\hline 7. IS impacts - results & $\begin{array}{l}\text { technology, } \\
\text { organizational, } \\
\text { business, change }\end{array}$ & $32 \%$ & Performance via IS \\
\hline 8. Analysis & analysis & $24 \%$ & IS research methods and theory \\
\hline $\begin{array}{l}\text { 9. Communications } \\
\text { Differences }\end{array}$ & Organisation, different & $17 \%$ & $\begin{array}{l}\text { Communication differences via } \\
\text { IS }\end{array}$ \\
\hline 10. IS impacts - firms & Firms, results, benefit & $13 \%$ & Benefits from IS \\
\hline
\end{tabular}

(1) Themes were identified and labelled initially by Leximancer then re-labelled by authors;

(2) Leximancer algorithm identifies concepts initially, these related concepts are then clustered in Themes.

(3) A measure of connectedness of the concepts within a particular theme, only connectivity above $10 \%$ was considered. 
Figure 3. IS Journals from 1990 to 1999: Main Themes and Concepts Map

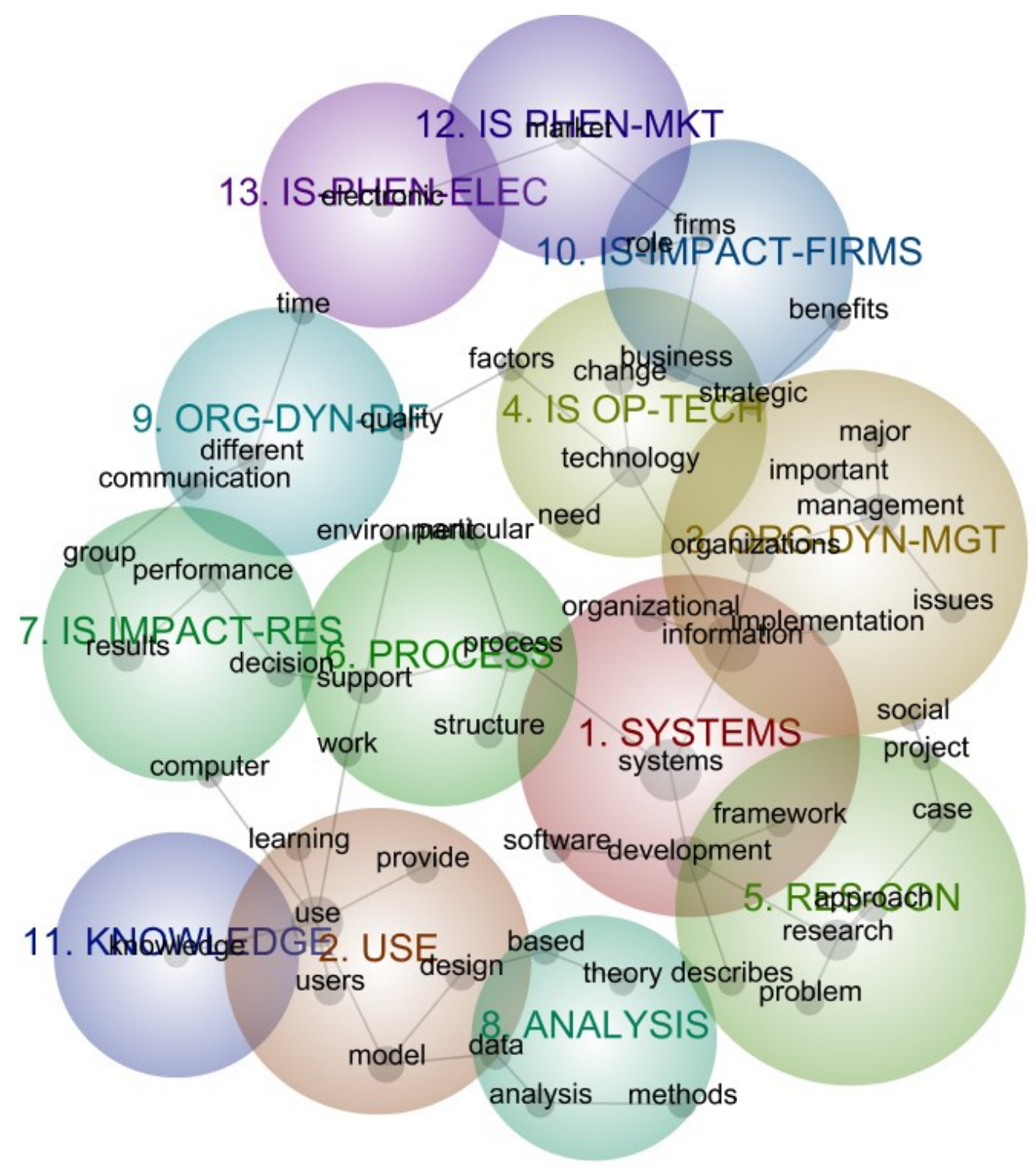




\subsection{The 2000's: IS processes and IS use}

Figure 4 and Table 3 below show that in the next decade (2000-2009) many (if not all) of the previous decade's themes and underlying concepts have been maintained to a higher or lesser degree. In addition, an increasing stage of dominance can be elicited by looking at the theme of organisational dynamics (theme 2) and IS use (theme 1). Both have increased their size and have also absorbed concepts that were previously associated with other themes in the previous period.

This dominance is complemented by a degree/stage of eclecticism in relation to the areas of study/application of IS: The theme of IS impacts-firms can be seen in direct competition with IS impacts-results, suggesting also that the IS field was aiming to generate outputs valuable to both research and practice-oriented audiences and to different geographical audiences (US and elsewhere).

Despite the dominance of IS use and in relation to previous studies of the IS field, it is insightful not to see the concept of 'acceptance' as dominating this theme. This suggests that activity in the IS use did not totally 'succumb' to the use of models like TAM (technology acceptance) and that connections with some 'dormant' concepts like systems or research have contributed to keep a healthy decree of eclecticism within it.

This can be confirmed by considering the presence of the 'systems' concept during this decade. Having lost its high-level association with 'information' from the previous one, this concept now mediates between themes of research implications for IS practice (theme 9) and research (theme 6). Acting again as a hinge, 'systems' is now an umbrella term to link different strands of research and practice in the IS field. Hirschheim and Klein (2012) claim that during this period the IS field consolidated scholarly activity in the form of journal articles, conferences and other fora. To this and similar claims about eclecticism in the IS field via competition (Córdoba-Pachón et al, 2012), it can be added that the 'systems' concept contributed a good deal to make them happen and maintain a healthy balance of research diversity. 
Table 3: Most prominent themes and concepts in the IS literature from 2000 to 2009

\begin{tabular}{|c|c|c|c|}
\hline $\begin{array}{l}\text { Theme (1) } \\
\text { (Abbreviation in map) }\end{array}$ & $\begin{array}{l}\text { Concepts Clustered in } \\
\text { each theme (2) }\end{array}$ & $\begin{array}{l}\text { Connectivity } \\
(3)\end{array}$ & $\begin{array}{l}\text { Focus for our Interpretation } \\
\text { of each Theme }\end{array}$ \\
\hline 1. Use & $\begin{array}{l}\text { use, model, provide, } \\
\text { different, analysis, users }\end{array}$ & $100 \%$ & $\begin{array}{l}\text { Model analysis of computer- } \\
\text { based use }\end{array}$ \\
\hline $\begin{array}{l}\text { 2. Organisational Dynamics } \\
\text { - process }\end{array}$ & $\begin{array}{l}\text { process, management, } \\
\text { organizations, business, } \\
\text { important, } \\
\text { implementation, software }\end{array}$ & $89 \%$ & $\begin{array}{l}\text { Management of } \\
\text { implementation and change } \\
\text { processes }\end{array}$ \\
\hline 3. Systems & $\begin{array}{l}\text { systems, development, } \\
\text { organizational, } \\
\text { understanding, work, } \\
\text { case }\end{array}$ & $74 \%$ & $\begin{array}{l}\text { Linking IS activity in } \\
\text { organisations with its } \\
\text { understanding via different } \\
\text { research perspectives and } \\
\text { approaches. }\end{array}$ \\
\hline 4. IS operations - Technology & $\begin{array}{l}\text { technology, support, } \\
\text { adoption, factors }\end{array}$ & $61 \%$ & $\begin{array}{l}\text { Technology adoption and } \\
\text { support }\end{array}$ \\
\hline 5. IS impacts - firms & $\begin{array}{l}\text { firms, performance, } \\
\text { relationship }\end{array}$ & $52 \%$ & $\begin{array}{l}\text { Performance and quality } \\
\text { impacts }\end{array}$ \\
\hline 6. Research concepts & $\begin{array}{l}\text { research, theory, } \\
\text { approach }\end{array}$ & $50 \%$ & $\begin{array}{l}\text { Methods, theory, approaches } \\
\text { for the IS field }\end{array}$ \\
\hline 7. IS impacts - results & results, data & $43 \%$ & Model-based, network impacts \\
\hline 8. Research concepts - design & design & $37 \%$ & Context-based IS design \\
\hline $\begin{array}{l}\text { 9. Research concepts }-I S \\
\text { implications }\end{array}$ & practice & $26 \%$ & $\begin{array}{l}\text { IS research implications for } \\
\text { practice }\end{array}$ \\
\hline $\begin{array}{l}\text { 10. Organisational dynamics } \\
\text { - knowledge }\end{array}$ & knowledge, project & $24 \%$ & $\begin{array}{l}\text { Organisational learning via } \\
\text { knowledge }\end{array}$ \\
\hline
\end{tabular}

(1) Themes were identified and labelled initially by Leximancer then re-labelled by authors;

(2) Leximancer algorithm identifies concepts initially, these related concepts are then clustered in Themes.

(3) A measure of connectedness of the concepts within a particular theme, only connectivity above $10 \%$ was considered. 
Figure 4. IS Journals from 2000 to 2009: Main Themes and Concepts Map

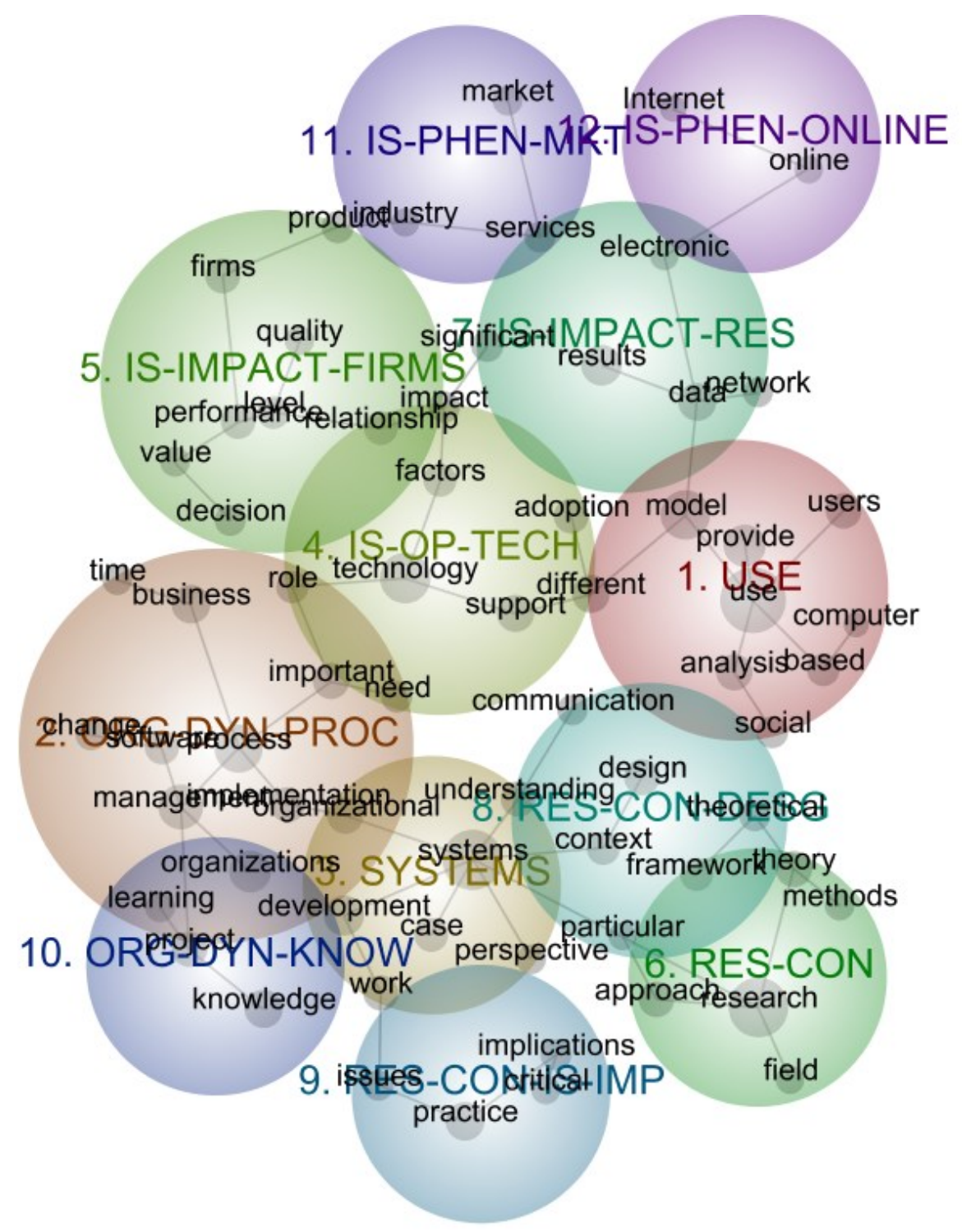




\subsection{From 2010 to date: The consolidation of IS use and rediscovery/resurfacing of 'information' and 'systems'}

As seen in Figure 5 and Table 4 below, the theme of IS use consolidates its dominance by absorbing concepts like social and network and by getting close to others like theory, technology and adoption. This finding confirms the dominance of IS research in the form of technology acceptance models from the 2000s and beyond (Córdoba-Pachón et al, 2012; Liu et al, 2016).

Nevertheless, and to maintain balance between dominance and eclecticism in IS use, there is a re-emerging information (theme 3 ) which has taken over previously dominant areas (i.e. organisational dynamics into management, theme 5). The previous theme of IS use has now gone beyond the realm of organisations and is now closely related to the theme of information use with new domains to explore including markets (theme 7) and online phenomena (theme 9). In connection with both information and use themes, the IS field keeps a degree of eclecticism in relation to different audiences interested in IS use (firms, organisations), the intended outputs of IS research (results, effects) and the different approaches being used (models, theories, cases).

Contributing to maintain dominance and eclecticism, the 'systems' concept has re-emerged or resurfaced again. Under the theme of research concepts (theme 8), 'systems' still connects IS research concepts with their now wider domains of application via 'information', 'technologies' and 'management' among others. Following Abbott (2001), it can be said that the resurfaced link between 'information' and 'systems' can be interpreted as a sign that IS this path of IS research and practice has been creatively extended by 'borrowing' the concept of theory (theme 8). In doing so, the IS field seems to have learned from others and this could have several implications that are discussed in the next section of the paper. 
Table 4: Most prominent themes and concepts in the IS literature from 2010 to2014

\begin{tabular}{|c|c|c|c|}
\hline $\begin{array}{l}\text { Theme (1) } \\
\text { (Abbreviation in map) }\end{array}$ & $\begin{array}{l}\text { Concepts Clustered in } \\
\text { each theme (2) }\end{array}$ & $\begin{array}{l}\text { Connectivity } \\
\text { (3) }\end{array}$ & $\begin{array}{l}\text { Focus for our Interpretation } \\
\text { of each Theme }\end{array}$ \\
\hline 1. Use & $\begin{array}{l}\text { use, model, data, social, } \\
\text { users, analysis, design }\end{array}$ & $100 \%$ & $\begin{array}{l}\text { Individual and collective IS } \\
\text { users phenomena of use } \\
\text { investigated via models }\end{array}$ \\
\hline 2. Information & $\begin{array}{l}\text { information, } \\
\text { technology, process, } \\
\text { support }\end{array}$ & $82 \%$ & $\begin{array}{l}\text { Knowledge, theory-informed } \\
\text { research/study approaches, } \\
\text { cases }\end{array}$ \\
\hline 3. Research concepts & $\begin{array}{l}\text { research, systems, } \\
\text { theory, literature, } \\
\text { approach }\end{array}$ & $71 \%$ & $\begin{array}{l}\text { Ubiquity of information } \\
\text { within and beyond } \\
\text { organisational systems and } \\
\text { also oriented to information } \\
\text { use; diversity in research }\end{array}$ \\
\hline 4. IS impacts - effects & effects, results, firms & $58 \%$ & $\begin{array}{l}\text { Long-term effects of IS } \\
\text { including quality }\end{array}$ \\
\hline $\begin{array}{l}\text { 5. Organisational dynamics - } \\
\text { management }\end{array}$ & $\begin{array}{l}\text { management, } \\
\text { organizations, project }\end{array}$ & $35 \%$ & $\begin{array}{l}\text { Process and project design in } \\
\text { organisations }\end{array}$ \\
\hline 6. IS impacts - performance & performance, business & $34 \%$ & $\begin{array}{l}\text { Role of IS in securing and } \\
\text { ensuring business } \\
\text { performance }\end{array}$ \\
\hline $\begin{array}{l}\text { 7. Other IS phenomena- } \\
\text { online }\end{array}$ & product, services & $30 \%$ & Online products and services \\
\hline 8. Research concepts - theory & practice, development & $30 \%$ & $\begin{array}{l}\text { Theory informed research and } \\
\text { modelling }\end{array}$ \\
\hline $\begin{array}{l}\text { 9. Other IS phenomena- } \\
\text { online/ digital }\end{array}$ & network & $11 \%$ & $\begin{array}{l}\text { Online, network and digital } \\
\text { phenomena }\end{array}$ \\
\hline
\end{tabular}

(1) Themes were identified and labelled initially by Leximancer then re-labelled by authors;

(2) Leximancer algorithm identifies concepts initially, these related concepts are then clustered in Themes.

(3) A measure of connectedness of the concepts within a particular theme, only connectivity above $10 \%$ was considered. 
Figure 5. IS Journals from 2010 to 2014: Main Themes and Concepts Map

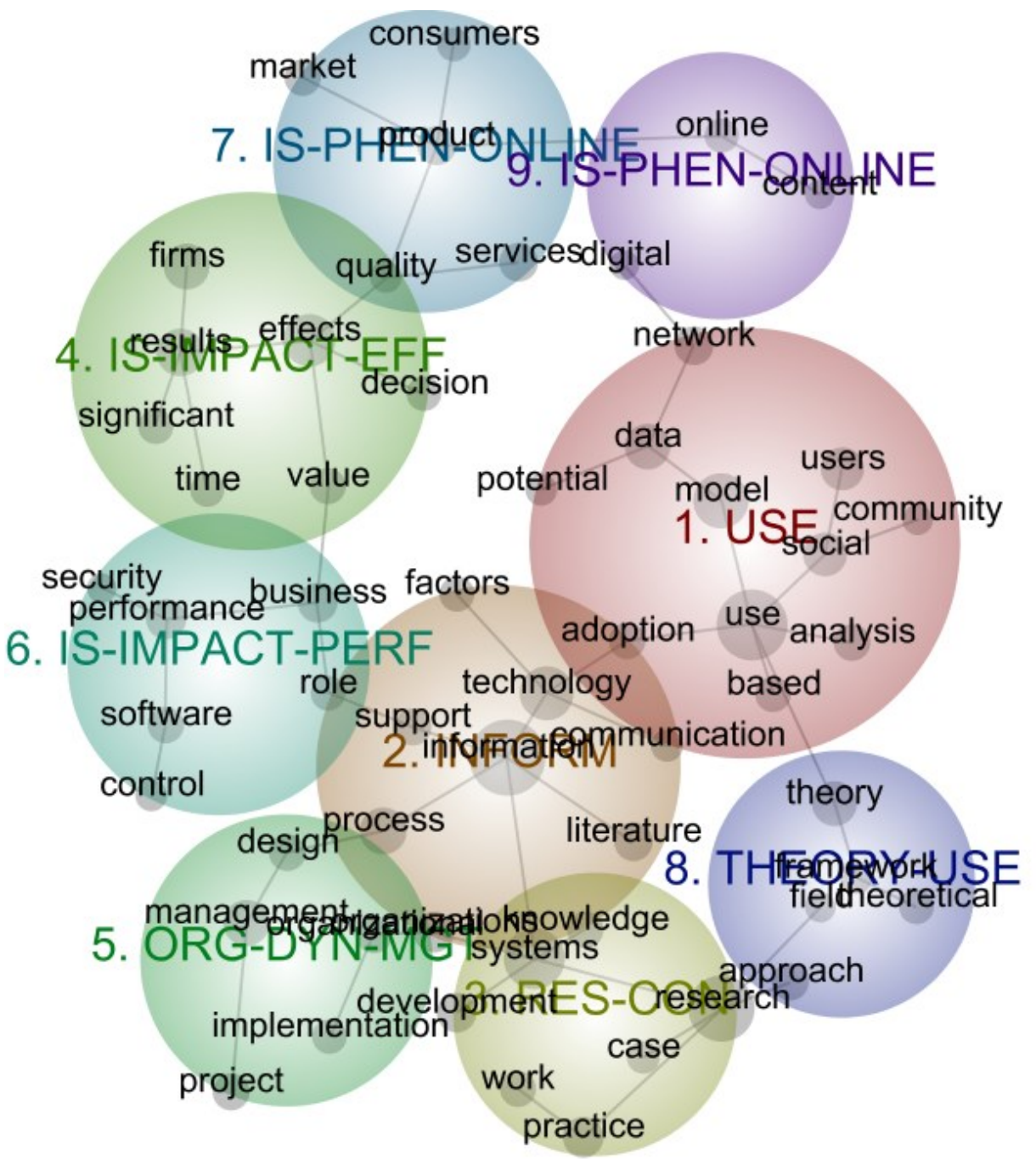




\section{Discussion}

Overall, it can be said that dominance and eclecticism have co-existed as mutually dependent stages in the IS field. Because of this, the IS field can be considered stable or fluid depending on the research perspective adopted. Previous accounts of the IS field have provided evidence of the importance of knowledge elements like the technology acceptance model (Sidorova et al, 2008; Córdoba-Pachón et al, 2012; Hirschheim and Klein, 2012; Liu et al, 2016). However, the adoption of a knowledge-related perspective to study the IS field has resulted in identifying some 'dormant' and 'obvious' concepts (information, systems and use) that seem to be overlooked and play key roles to both explain where the IS field has been and where it could go next (Lee, 2010).

Perhaps more importantly than confirming that knowledge in IS surfaces or resurfaces is what to do about it (Abbott, 2001; Lee, 2010). Concepts like 'systems', 'information' and 'use' remain in the field, often 'visible' whilst 'hidden'. Visible as they have contributed to laid out areas of IS study (IS development, organisational dynamics, online settings) and set out ways to study them (one of them being systems thinking). 'Hidden' as these concepts have remained in the field and often articulating diverse research perspectives, tools or methods, contributing to the avoidance of 'extremes' when it comes to study IS phenomena from dominant or eclectic research perspectives.

In this regard, it is of particular relevance to consider how the 'systems' concept has contributed to the IS field. Different from concepts like information, management or use, 'systems' is part of the DNA of the IS field by contributing to its unfolding in multifarious ways. First as a hinge to bring different research traditions to influence the IS field (1990s) to then help consolidate research and practice in it (2000s) to then act as a hinge again to facilitate further expansion of the field via areas like information and use (2010s onwards).

Moreover, 'systems' can be regarded as an IS knowledge concept that has helped linked both dominance and eclecticism stages in the IS field so that relevant knowledge is retained. Systems has brought 'new' areas of study into play (i.e. information systems, management information systems, decision systems, other organisational systems, online systems); and on the other, it has brought diverse research-and practice knowledge elements to them. When speaking about resurfacing of knowledge, Abbott (2001) considers how some concepts remap even into their competitors through the cyclical nature of knowledge described earlier in the paper. Contrary to what Abbott (2001) and Lee (2010) seem to suggest, in our study of the IS 
field the results show that albeit not playing a unique role, the remapping of 'systems' does not necessarily 'skip' cycles; but becomes part of different knowledge paths or lineages, some of which result in the resurfacing of information-systems and research associations that are key to both the unfolding and rediscovery of the IS field.

From these insights, there could be several implications for IS research. Despite a high-level dominance (mostly in US based IS journals) of positivist-oriented research (Chen and Hirschheim, 2004; Love and Hirschheim, 2016), our study highlights that for this or any other research paradigm that guides future research, it is important to maintain the notion of the systemic nature of IS phenomena that is being studied. This nature seems at times be lost to cause-effect models or frameworks.

The often 'obvious' or 'dormant' systems concept/theme could help IS researchers not forget the importance of reflecting on the boundaries that are used to frame and study IS phenomena (Córdoba-Pachón and Midgley, 2008; Córdoba-Pachón et al, 2012). Information systems researchers could be creative about defining new boundaries by 'borrowing' methods from other fields or redefining IS phenomena using analogies already tried elsewhere (Abbott, 2004). In doing so, they should however keep in mind that the 'systems' concept is what society needs from the IS field to retain. As Lee (2010) advocates, it becomes important to consider that this concept cannot be explored or used uncritically in isolation from others (information, technology, organisation)

Furthermore, the findings suggest that in 25 years, dominance and eclecticism in IS have been somehow limited. Despite periods being different from each other, associations between concepts and themes have been somehow not very different from one period to another. With the dominance of technology acceptance models that is being confirmed in previous studies of the field (Sidorova et al, 2008; Hirschheim and Klein, 2012; Liu et al, 2016), IS field has grown used to recreate these associations because doing so helps it maintain its relevance, participation and legitimacy in social sciences. However, new and more reflective combinations and borrowings between the concepts of information, systems and use could help the IS field to consider future possibilities (Lee, 2010). For example, what if what is considered information is not necessarily linked to technology or use, or what if what is considered a system is not necessarily linked to information or organisations? What if, as Córdoba-Pachón et al (2012) suggest, we could go beyond exploring IS use from non-positivist or model-based perspectives? Exploring new or historically emergent 
combinations and re-combinations between IS knowledge concepts or themes within as well as outside the IS field could help expand the realm of possibilities for the future without losing consideration of the importance of the 'systems' concept in bringing them together.

Educationally, the IS field is still at crossroads regarding how to prepare future researchers and practitioners so that they know where the field has been and where it can go next (Hirschheim and Klein, 2012). There are possibilities to dialogue on equal footing with other fields of knowledge (Bernroider et al, 2013), but these possibilities would need to consider some common grounds and somehow a common ancestry between fields in relation to where they have been before (Abbott, 2004).

Our findings suggest that the IS field tends to 'hide' some key concepts (systems, information, use) in the search for what appear to be more fashionable or popular ones (technology, online, markets). The historical unfolding of these concepts could be rediscovered and transmitted to IS student generations, also with the help of other fields of knowledge where similar stories about dominance and eclecticism in the light of some key concepts could be identified.

In this regard, Hirschheim and Klein (2012)'s plea to keep the history of IS alive for the benefit of new generations could be put in practice with conversations with other fields, settlements and disciplines. The field of IS could become more aware of other locations where paths to relevant IS knowledge could be explored or rediscovered, and their limitations and possibilities ascertained. Perhaps like the IS field there could be other fields which suffer from a similar type of memory loss (i.e. systems thinking, management, organisational studies, psychology or sociology). Research, practical and educationally oriented efforts in IS could show positively show students or newcomers this memory loss but also its rediscovery in the broader context of the unfolding of knowledge in society.

Therefore, and for future practice in IS academia and beyond, the IS field can venture in exploring new areas where situations can be translated into IS related phenomena. In different analytical locations (i.e. industry), there could be perceived cycles of dominance or eclecticism from other disciplines or settlements. IS researchers and practitioners could learn from enhancing their dialogue opportunities with others, as well as venturing into studying new locations. IS practitioners could benefit from borrowing and rediscovering the use of concepts like 'systems', 'information' and 'use'. Learning could be fostered by enabling 
mutual appreciation of the uniqueness of IS knowledge regardless of where it is 'owned' in social sciences.

It is worth remembering that under the perspective adopted to study the IS field proposed in this paper, it is society the ultimate judge of what counts or could count as valuable knowledge. Rather than making us run to protect what we think is 'ours', this insight could make us more open and humble to what the future can bring us together. As individuals interested in the IS field, this perspective could encourage us to 'borrow' and 'translate' 'new' stories as well as ideas, even if it means arriving at similar points in the IS maze that we think we already know (Abbott, 2001). However, there could be different routes and adventures that we could unearth for the benefit of the field and of our societies in general.

\section{Concluding remarks, limitations and further research}

In this paper, it has been argued that existing frameworks and studies of the dynamics of the IS field could be enhanced by focusing on the cyclical and potentially resurfacing nature of IS knowledge in society. A systemic perspective and framework has been developed to better understand the dynamics of IS academic knowledge, and an empirical analysis of content of a sample of IS abstract articles from eight IS journals has been conducted to further explore these.

Our findings and interpretations suggest that key concepts like systems, information and use, their relationships and associations contribute to keep the IS field as a socially relevant one. These and other concepts help the field develop dominance and eclecticism and maintain mutual relationships between these stages. They do so by bringing together different strands of IS research and practice, resulting in the avoidance of extremes and thus in the potential loss of diversity in the field. They could also hold key insights for developing the future of the field.

Exploring new knowledge combinations and lineages leading to or departing from these concepts could offer the IS field a richer history and foster creativity for its future. IS researchers and practitioners could venture to explore problems of non-IS use, generating other ways to understand IS use, or challenging traditional research and practice strategies beyond the realm of organisations. New combinations and re-combinations between IS concepts and themes as well as their further dialogue with other fields could help as Bryant 
(2008) advocates to maintain a continuous and creative attitude towards what the IS field is or should be about, even if this means going against what is being regarded as potentially acceptable or publishable at a time.

Our hope is that this paper provides an inspiration to people working in this field to creatively venture in exploring the IS 'maze' in different ways that is has been the case and learn from what they or others achieve in doing so. Creativity in the IS maze could then take an insightful direction: To explore knowledge that has been generated in the field as resulting from rediscoveries within or beyond it; to borrow neighbouring knowledge elements and their associations; to value each other's histories of contributing to societal dynamics; and to accept that the enterprises of dominance and eclecticism in IS and beyond are never ending. Creativity in IS could then become a way to overcome perceived knowledge by fostering both dominance and eclecticism in the field.

In terms of limitations, we are aware that, in this paper, the core of the trends on the development of IS have been analysed with the aid of a software data mining algorithm such as Leximancer ${ }^{\circledR}$. This could have limited the generation of concepts or associations in a more detailed level of analysis to inform future IS academic research, education and practice. We are also aware of our own bias when interpreting and naming the themes generated by the software and of some inherited bias when dividing our analysis in decades and a half-adecade period. To overcome these, finer or more detailed analysis could be further conducted. Moreover, our sample could have included extended periods of time (2015-2018) and by including other IS and non-IS journals.

For future research we would like to review the above limitations and complement this study by: (a) corroborating the insights obtained with a more in-depth and detailed micro-level analysis of a set of exemplar articles, from each of the journals analysed here; (b) extending our analysis to include journals of other fields (i.e. accounting, operations management, technology management) in order to identify, contrast and compare cycles of knowledge dominance, eclecticism or rediscovery and future possibilities for dialogue with these fields; (c) including sources of IS practitioners' data (i.e. trade magazines or other electronically available content) to assess the different impacts that academic IS knowledge could be having in practice and (d) explore in more detail the different associations of key concepts that have 
been identified in this study (systems, information, use) with a view to potentially generate a theory of how IS knowledge is cyclically generated and rediscovered.

\section{References}

Abbott, A. (1988) The System of Professions: An Essay on the Division of Expert Labor, Chicago, University of Chicago Press.

Abbott, A. (2001) Chaos of Disciplines. Chicago, University of Chicago Press.

Abbott, A. (2004) Methods of Discovery: Heuristics for the Social Sciences. USA, W.W. Norton \& Company Inc.

Bandara W., Furtmueller, E., Gorbacheva, E., Miskon, S \& Beekhuyzen, J. (2015) Achieving rigor in literature reviews: Insights from qualitative data analysis and tool support. Communications of the Association for Information Systems (CAIS) 34(8), pp. 154-204.

Baskerville, R., \& Myers, M. (2002) "Information Systems as a Reference Discipline," MIS Quarterly 26 (1), pp. 1-14.

Benbasat, I., \& Zmud, R. (2003) "The Identity Crisis within the IS Discipline: Defining and Communicating the Discipline's Core Properties," MIS Quarterly 27(2), pp. 183-194.

Bernroider, E., Pilkington, A. and Córdoba- Pachón, J.R., 2013. Research in information systems: a study of diversity and inter-disciplinary discourse in the AIS basket journals between 1995 and 2011. Journal of Information Technology, 28, pp. 74-89.

Bryant, J. (2008) "The Future of Information Systems - Thinking Informatically," European Journal of Information Systems 17(6), pp. 695-698.

Chen, W. and Hirschheim, R. (2004). A paradigmatic and methodological examination of information systems research from 1991 to 2001. Information Systems Journal 14(3), pp. 197-235.

Córdoba-Pachón, J.R., Pilkington, A. \& Bernroider, E. (2012) "Information Systems as a Discipline in the Making: Comparing EJIS and MISQ between 1995 and 2008," European Journal of Information Systems 21(5), pp. 479-495.

Córdoba-Pachón, J.R, and Midgley G., (2008) Beyond organisational agendas: using boundary critique to facilitate the inclusion of societal concerns in information systems planning. European Journal of Information Systems, 17 (2), pp. 125-142.

Cretchley, J., Rooney, D., \& Gallois, C. (2010) Mapping a 40-Year History with Leximancer: Themes and Concepts in the Journal of Cross-Cultural Psychology, Journal of CrossCultural Psychology 41(3), pp. 318-328.

Davis, G. (2000) "Information Systems Conceptual Foundations: Looking Backward and Forward." Organizational and Social Perspectives on Information Technology, R. Baskerville, J. Stage and J. DeGross (eds.), Boston: Kluwer.

Galliers, R., (2003) Change as crisis or growth? Toward a trans-disciplinary view of information systems as a field of study - a response to Benbasat and Zmud's call for returning to the IT artefact. Journal of the Association for Information Systems, 4(6), pp. 337-351.

Hassan, N. (2011) "Is Information Systems a Discipline? Foucauldian and Toulminian Insights," European Journal of Information Systems (20), pp. 456-476. 
Hassan, N., Mathiassen, L. (2017). Distilling a body of knowledge for information systems development. Information Systems Journal, forthcoming. Available online at: http://onlinelibrary.wiley.com/doi/10.1111/isj.12126/full, accessed March 2017.

Hirschheim, R. and Klein, H. (2012). "A Glorious and Not-So-Short History of the Information Systems Field". Journal of the Association for Information Systems (JAIS) 13(4), 188-235.

Klein, H. K., \& Hirschheim, R. (2008) "The Structure of the IS Discipline Reconsidered: Implications and Reflections from a Community of Practice Perspective," Information and Organization 18(4), pp. 280-302.

IIvari, J., Hirschheim, R. \& Klein, H.K. (2004) "Towards a Distinctive Body of Knowledge for Information Systems Experts: Coding ISD Process Knowledge in Two IS Journals," Information Systems Journal (14), pp. 313-342.

Lee, A. (2010). Retrospect and prospect: Information systems research in the last and next 25 years. Journal of Information Technology (25), pp.336-348.

Love, J. \& Hirschheim, R. (2016). Reflections on Information Systems Journal Thematic Composition. Information Systems Journal 26(1), pp.21-38

Liu, Y., Li, H., Goncalves, J., Kostakos, V., Xiao, B. (2016). Fragmentation or cohesion? Visualising the process and consequences of information systems diversity, 1993-2012. European Journal of Information Systems 25(6), pp. 509-533.

Paré, G., Trudel, M.C, Jaana, M.\& Kitsiou, S. (2015). Synthesising information systems knowledge: a typology of literature reviews. Information and Management (52), pp. 183199.

Rowe,F. (2014). What literature review is not: diversity, boundaries and recommendations. European Journal of Information Systems 23(3), pp.241-255.

Schwartz, D. (2014) Research commentary - the disciplines of information: lessons from the history of the discipline of medicine. Information Systems Research 25(2), pp. 205-221.

Sidorova, A., Evangelopoulous, N., Valacich, J. \& Ramakrishan, T. (2008). Uncovering the intellectual core of the information systems discipline. MIS Quarterly 32(3), pp. 467-482.

Smith, A.E. \& Humphreys, M.S. (2006) Evaluation of unsupervised semantic mapping of natural language with Leximancer concept mapping. Behavior Research Methods, vol. 38, no. 2 , pp. 262.

Smith, A.E. (2003). Automatic extraction of semantic networks from text using Leximancer, Proceedings of the 2003 Conference of the North American Chapter of the Association for Computational Linguistics on Human Language Technology: Demonstrations-Volume 4 Association for Computational Linguistics, 23 pages.

Taylor, H., Dillon, S. \& Van Wingen, M. (2010) Focus and diversity in information systems research: meeting the dual demands of a healthy applied discipline. MIS Quarterly, 34(4), pp. 647-667.

Vessey, Iris \& Ramesh, Venkataraman \& L. Glass, Robert. (2002). Research in Information Systems: An Empirical Study of Diversity in the Discipline and Its Journals. J. of Management Information Systems 19, pp.129-174.

Wade, M., Biehl, M., \& Kim, H. (2006). Information systems is not a reference discipline (and what we can do about it). Journal of the Association for Information Systems 7(5), pp. 247-269. 
Wagner, G., Prester, J., \& Schryen, G. (2017). Exploring the scientific impact of information systems design science research: A scientometric study. Thirty Eight International Conference in Information Systems (ICIS). Seoul, South Korea, 28 pages. Available at: https://epub.uni-regensburg.de/36209/1/ICIS2017-Revision.pdf, accessed July 2018.

Weber, R.P. (1990) Basic Content Analysis. Newbury Park California, Sage. 